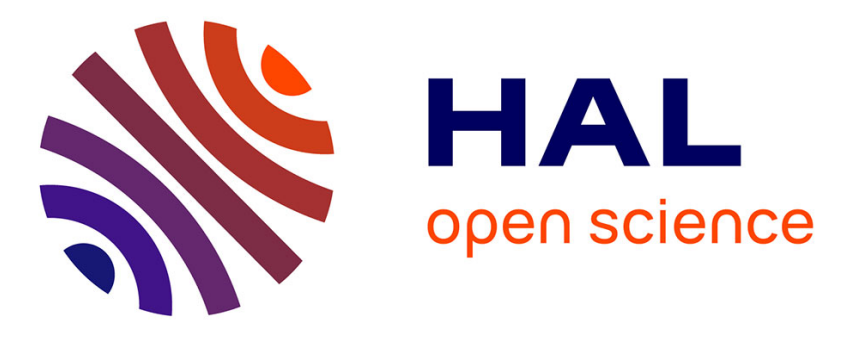

\title{
Electrochemical Fluorescence Switch of Organic Fluorescent or Fluorogenic Molecules
}

Manon Guille-Collignon, Jérôme Delacotte, Frédéric Lemaître, Eric Labbé, Olivier O. Buriez

\section{- To cite this version:}

Manon Guille-Collignon, Jérôme Delacotte, Frédéric Lemaître, Eric Labbé, Olivier O. Buriez. Electrochemical Fluorescence Switch of Organic Fluorescent or Fluorogenic Molecules. Chemical Record, 2021, 10.1002/tcr.202100022 . hal-03160343

\section{HAL Id: hal-03160343 \\ https://hal.sorbonne-universite.fr/hal-03160343}

Submitted on 5 Mar 2021

HAL is a multi-disciplinary open access archive for the deposit and dissemination of scientific research documents, whether they are published or not. The documents may come from teaching and research institutions in France or abroad, or from public or private research centers.
L'archive ouverte pluridisciplinaire HAL, est destinée au dépôt et à la diffusion de documents scientifiques de niveau recherche, publiés ou non, émanant des établissements d'enseignement et de recherche français ou étrangers, des laboratoires publics ou privés. 
Electrochemical Fluorescence Switch of Organic Fluorescent or Fluorogenic Molecules

Manon Guille-Collignon, ${ }^{[a]}$ Jérôme Delacotte, ${ }^{[a]}$

Frédéric Lemaître, ${ }^{[a]}$ Eric Labbé, ${ }^{[a]}$ and Olivier

Buriez *[a]
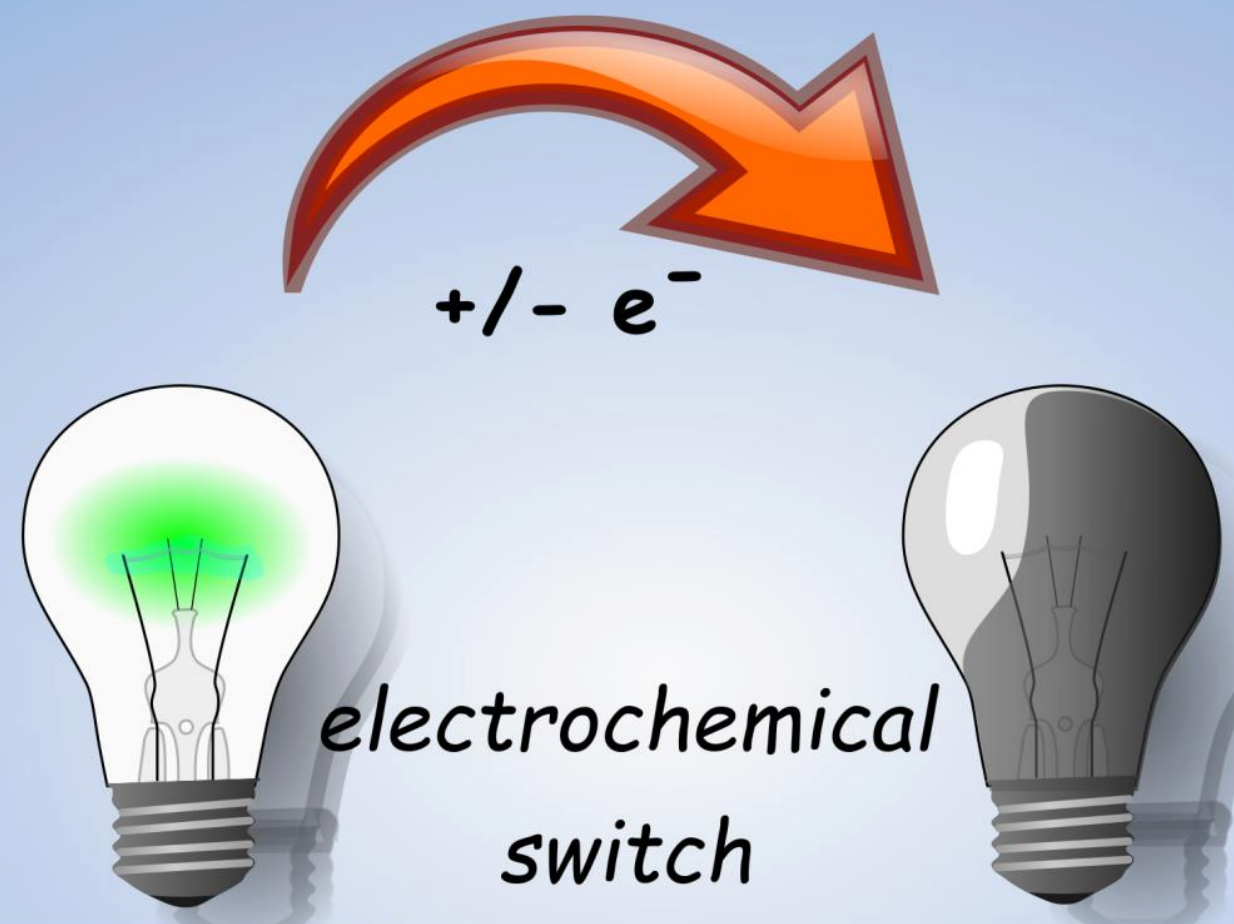

FLUORESCENCE ON

FLUORESCENCE OFF

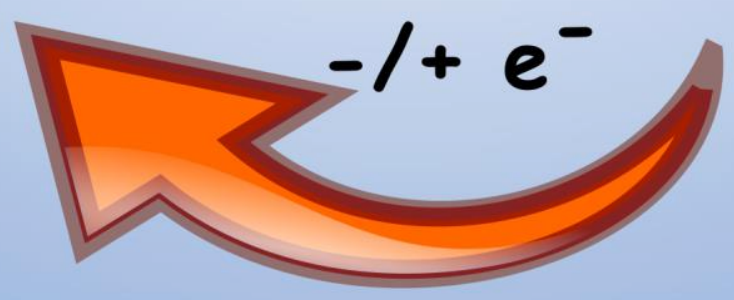


Abstract: This short review is aimed at emphasizing the most prominent recent works devoted to the fluorescence modulation of organic fluorescent or fluorogenic molecules by electrochemistry. This still expanding research field not only addresses the smart uses of known molecules or the design of new ones, but also investigates the development of instrumentation providing time- and space-resolved information at the molecular level. Important considerations including fluorescent/fluorogenic probes, reversible/irreversible fluorescence switch, direct/indirect fluorescence modulation, or environment properties are especially scrutinized in recent works dealing with bioanalysis perspectives.

\section{Introduction}

In recent years, the interest in stimuli-responsive molecules encompassing thermal, photonic, electric, $\mathrm{pH}$...external triggers has grown rapidly with the multiplication of applications such as the reversible control of molecular memories, molecular logic gates, ion sensing, bioanalysis and fluorescence imaging. Accordingly, electrochemical commands aimed at modulating the fluorescence of molecules have been particularly explored, notably in analytical and bioanalytical chemistry, considering that many analytes are redox-active and can be detected/mapped with high sensitivity through fluorescence. With this respect, numerous organic and organometallic dyes, dyads, triads, or polymers exhibiting both fluorescence and redox properties are continuously developed and investigated [1, 2]. In parallel, instrumental methodologies aimed at synchronizing electrochemical stimulation and fluorescence detection have been developed to provide reliable time- and space-resolved responses, as well as information at the molecular level $[3,4]$. Two types of electrochemical fluorescence switch can be obtained depending on the redox starting state of the molecule. Hence, a molecule is said fluorescent when it is emissive in its stable/original form and less or non-emissive when oxidized or reduced. Conversely, when a molecule is poorly emissive (or nonemissive) in its starting state but becomes emissive when oxidized or reduced, it is called fluorogenic. From the electrochemical point of view, the switch on/off of fluorogenic/fluorescent molecules may appear reversible, as this is related to the stability of the electrogenerated new redox state. Nevertheless, both reversible and irreversible situations may be interesting as a function of the targeted applications. Whatever the intrinsic photo-redox and chemical properties of these molecules, their fluorescence may also strongly depend on the physico-chemical parameters of their surrounding environments (polarity, $\mathrm{pH}$ ).

This article reviews some essential fluorescent and fluorogenic organic probes used in molecular electrochemistry with a special emphasis on recent works having potential applications in bioanalysis. It does not ambition to provide an exhaustive list of organic electrochemically-activable fluorescent or fluorogenic molecules. Actually, it surveys the most prominent recent works achieved in this field through illustrative examples. The first paragraph deals with the direct electrochemical switch (reversible or not) of some important fluorescent organic molecules in polar and non-polar environments. In the second paragraph, a focus is made on fluorogenic molecules whose fluorescence modulation is electrochemically promoted either directly or indirectly. A specific paragraph is devoted to $\mathrm{pH}$-responsive fluorogenic probes possessing redox properties.

It is noteworthy that most of the redox organic fluorescent dyes described in the first paragraph may also behave as fluorogenic species when they are covalently connected to a redox unit. In this case, molecules are generally non-emissive under photonic excitation due to a photoinduced electron or an energy transfer process. Oxidation or reduction may prevent this transfer either by a direct change of the redox state for photoinduced electron transfer or indirectly by shifting the absorption features in the case of energy transfer. Combination of rhodamine and ferrocene [5] or BODIPY (4,4-difluoro-4-bora-3a,4a-diaza-s-indacene) and a fullerene $C_{60}[6]$ are two typical examples recently investigated. Similarly, fluorescence of BODIPY was quenched when adsorbed at a gold metal surface whereas luminescence was only observed for molecules reductively desorbed and then separated from the electrode surface [7]. For all these developments the readers are invited to refer to recent relevant reviews [1 - 4]. [a] Dr M. Guille-Collignon, Dr J. Delacotte, Prof. F. Lemaître, Prof. E. Labbé, Dr O. Buriez

PASTEUR, Département de Chimie, Ecole Normale Supérieure, PSL University, Sorbonne Université, CNRS, 75005 Paris, France. E-mail: Olivier.buriez@ens.psl.eu 
Manon Guille-Collignon achieved her Ph.D. in 2005 in the field of physico-chemisty of exocytosis and nitric oxide effects on neurovascular coupling, from the Université Pierre \& Marie Curie, Paris 6, France. During her postdoctoral research at University of Warwick in 2005, in Coventry, UK (Marie-Curie Fellowship; direction of Dr. J.V. Macpherson), she worked on the electrochemical properties of single wall carbon nanotubes. She reached an Assistant Professor position in September 2006 in Université Pierre \& Marie Curie, now Sorbonne Université. Manon's research interests focus on bioelectrochemistry, microfluidics and bioenergetics via combined fluorescent and electrochemical measurement to study cellular secretion, oxidative stress and photosynthesis.

Jérôme Delacotte received his $\mathrm{PhD}$ in soft matter physics from Université Paris VII, (Paris, France) in 2009. His PhD work focused on physical chemistry and dynamics of thin liquid films, under the supervision of Dr. Langevin and Dr. Rio. Then, as a postoctoral research fellow at the Laboratoire de Physique Statistique (Paris, France), he opened to biophysics of lipid droplets and lipid membranes. In 2013, he was appointed associate professor in chemistry at the École Normale Supérieure in Paris. Jérôme is interested in multidisciplinary approaches at the physical-chemical-biological interface to study cellular organelles dynamics and photosynthesis.

Frédéric Lemaître did a joint thesis between the Université de Bourgogne (France) and the Université de Sherbrooke (Canada). He received a double $\mathrm{Ph}$. D. degree in 2003. His Ph. D. research dealt with electrochemistry of palladium clusters and their reactivity towards alkyl- and acyl halides. After doing postdoctoral research in the electrochemistry group at the Ecole Normale Supérieure de Paris (palladium catalysis - Heck reaction), he has been obtained an Assistant Professor

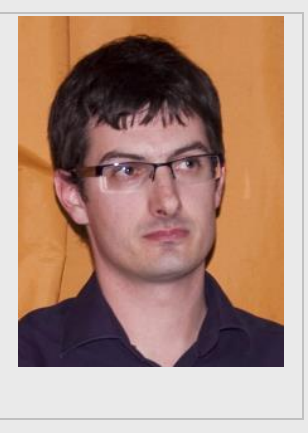
position at the Université Pierre et Marie Curie - Sorbonne Université in 2004. His research works concern bioelectrochemistry and especially the detection of secretion processes at the single cell level. Full professor in Sorbonne Université since 2020 , he is also interested in the production of bioelectricity by using photosynthesis.
Eric Labbé received his $\mathrm{PhD}$ in Analytical Chemistry in 1992 from Université Pierre et Marie Curie (now Sorbonne Université, Paris, France). He studied electrosynthetic mechanisms in the group of Jacques Périchon on nickel and cobalt-catalyzed processes. Since 2006, he is Professor at Sorbonne Université and his research topics concern the electroanalytical determination of reaction mechanisms, drug metabolism and drug vectorization.

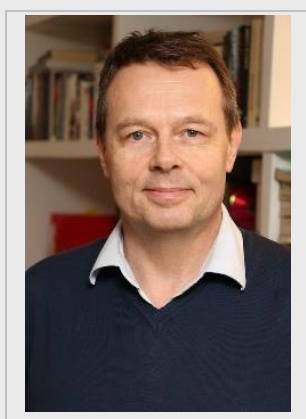

Olivier Buriez is a Research Director a CNRS. During his PhD at the École Normale Supérieure (Paris, France) and postdoctoral research at the Berkeley lab. (LBNL, Univ. of California, USA), he investigated the structure-activity relationships and mechanistic aspects of (bio)-organometallic compounds by electrochemistry. Since 1999, when he joined the CNRS, his research interests center on the electroanalytical determination of reaction mechanisms to

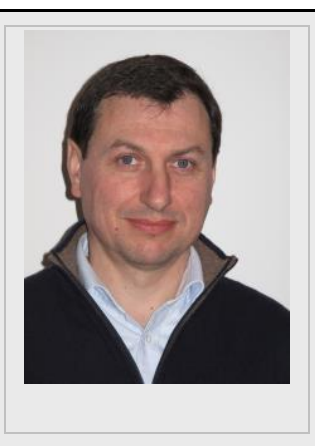
provide answers in fundamental fields such as catalysis, synthesis, analytical chemistry and molecular biology. Within this context, part of his work also includes the development of analytical methodologies and devices combining electrochemical and luminescence techniques. From 2015 to 2020, he was elected Officer of the Molecular Electrochemistry Division of the International Society of Electrochemistry (ISE).

\section{Direct electrochemical switch of organic fluorescent molecules}

The use of molecules whose luminescent properties are directly related to their redox state is a straightforward way to electrochemically modulate fluorescence. In that respect, a direct electrochemical switch has been evidenced on various families of redox-fluorescent organic molecules. These molecules generally possess a rigid aromatic or $\pi$-conjugated backbone because molecular motions like rotation or vibration are well-known nonradiative de-excitation pathways. Moreover, fused aromatic rings, possibly incorporating heteroatoms $(\mathrm{N}, \mathrm{O}, \mathrm{S})$ are recurrent substructures of organic fluorophores (Figure 1). On the one hand, situations where fluorescence modulation can be directly and reversibly achieved by electrochemistry are particularly targeted in the development of electrofluorochromic devices. Such situations require the electrogenerated species to be stable enough to be reduced/oxidized back into the initial stable redox state. On the other hand, a quest for an irreversible electrochemical switch may be relevant notably to discriminate between two different molecular populations. In the following, both reversible and irreversible switches are presented. 


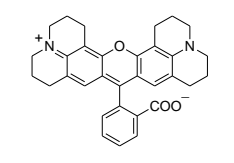

Rhodamine 101 [9]

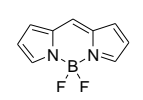

Bodipy [13-15]

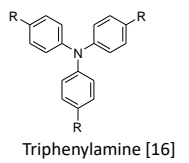

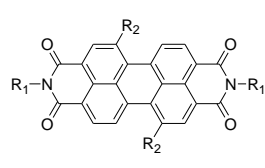

Perylenediimide [10]
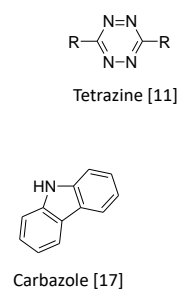

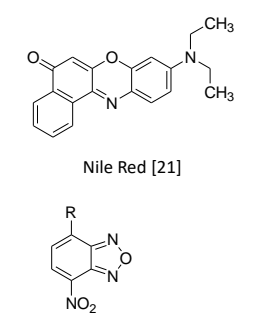

NBD [22, 24]

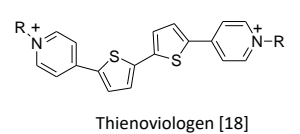

Figure 1. Chemical structures of some important redox-organic fluorescent molecules whose fluorescence can be directly modulated by electrochemistry.

Rhodamine derivatives such as rhodamine $6 \mathrm{G}$ (R6G) or rhodamine 101 (R101) are known as standards for quantum yield determinations. They are typical electrofluorochromic probes whose fluorescence can be directly and reversibly modulated by electrochemistry. Yet, in 2001, first electrochemical investigations of the R6G molecule, at a gold electrode surface and in aqueous solution, showed an irreversible reduction process associated to the strong adsorption of the probe on gold material [8]. Nevertheless, modification of the gold electrode surface with 4,4'bipyridine suppressed the adsorption step and led to a quasireversible one-electron process. Under these conditions, spectroelectrochemistry investigations showed a progressive fluorescence decrease under reduction of R6G while the starting luminescence could be recovered under re-oxidation of the $R 6 G$ reduced form [8]. More recently, the commercially available R101 has been investigated in a polar organic solvent such as acetonitrile: it was established that the radical form of $\mathrm{R} 101$, obtained upon mono-electronic electrochemical reduction, was non-fluorescent. Furthermore, fluorescence emission could be recovered by switching the potential to a value positive enough to allow the re-oxidation of the radical, establishing the electrofluorochromic properties of R101. Interestingly, multiple On/Off fluorescence switch events could be observed during several minutes, demonstrating the reversibility of the redox activation/deactivation process (Figure 2) [9].
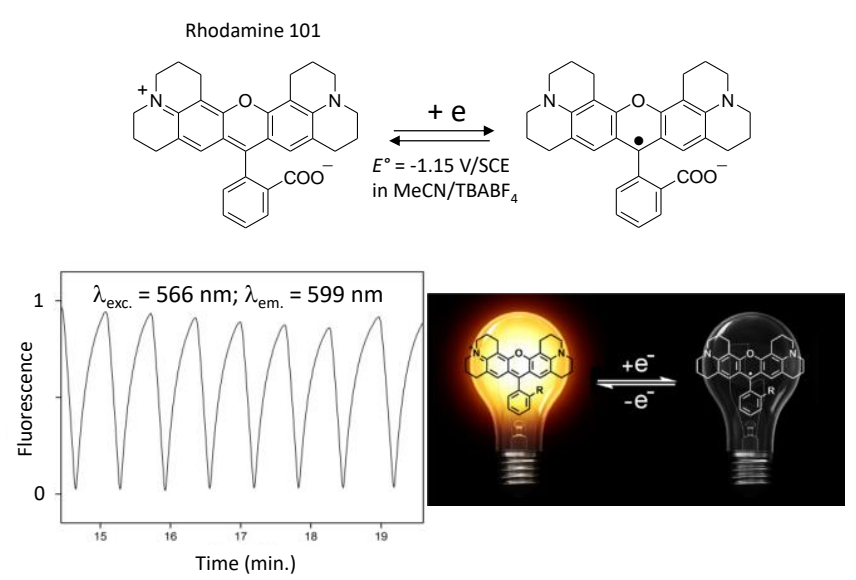

Figure 2. Direct reversible electrochemical switch of rhodamine 101 (adapted from ref. [9]).

Perylene diimides are another family of redox-fluorescent organic compounds which are popular thanks to their i) emission in the visible spectrum, ii) their strong absorption and fluorescence, iii) their good thermal, chemical, and photochemical stability. As a representative example, the electrochemical behavior of perylene dipentylimide displayed in dichloromethane two fully reversible one-electron reduction processes at -0.38 V/SCE and $-0.58 \mathrm{~V} / \mathrm{SCE}$ ascribed to the formation of an anion and a dianion, respectively [10]. Under successive electrochemical reduction / oxidation switches $(0 \rightarrow-0.8 \rightarrow 0 \rightarrow$ $-0.8 \mathrm{~V} / \mathrm{SCE}$ etc...$)$ the fluorescence of perylene dipentylimide $\left(\lambda_{\mathrm{ex}}\right.$ $=480 \mathrm{~nm} ; \lambda_{\mathrm{em}}=540 \mathrm{~nm}$ ) decreased and increased accordingly. It was further shown that the quenching of fluorescence coincided with the first reduction peak.

In 2006, it was established for the first time that tetrazine derivatives could undergo reversible electro-fluorescent switches thanks to the design of an electrofluorochromic system allowing fast potential switching, thus limiting the time window required for side reactions to proceed [11]. Accordingly, the starting fluorescent chloro-methoxytetrazine became non-emissive when a negative potential value was applied (electroformation of the corresponding anion-radical and dianion). Importantly, most of the fluorescence was restored through the application of a positive potential value (oxidation) regenerating the starting neutral molecule. Such electro-fluorescence switching was found to be reversible upon repetitive cycling.

Compounds based on the BODIPY skeleton (4,4-difluoro-4bora-3a, 4a-diaza-s-indacene) constitute a large class of fluorophores [12] notably for bioimaging applications. The narrow absorption/emission bands in the visible region and high fluorescence quantum yields of the 4,4-difluoro-4-bora-3a,4adiaza-s-indacene core are key characteristics of BODIPY-based bio-labels and sensors, which also benefit from the synthetic tunability of their optical properties, photostability, and solubility. Generally, BODIPY derivatives can be reversibly oxidized into a non-emissive cation radical $[13,14]$. Among the most relevant modifications of the BODIPY core, the substitution of carbon by nitrogen between the two pyrrolic units shifted the emission in the 
NIR range. Such aza-BODIPY derivatives are nice examples of NIR emissive electrofluorochromic compounds [15].

Triphenylamine derivatives also constitute a family of very promising candidates for applications in electrofluorochromism. Similarly to BODIPY, redox potential, fluorescence wavelength and intensity can be tuned according to the nature of the substituent on the triphenylamine core. Triphenylamine derivatives generally exhibit moderate to high fluorescence quantum yields in their neutral state whereas their corresponding electrogenerated cation-radicals are non-fluorescent. Though fluorescence switching could be achieved from both electrodonating and electro-withdrawing substituted triphenylamines, donor groups stabilize the radical cation, a feature recommended for the fabrication of electrofluorochromic materials [16].

Interestingly, some molecules display both electrochromic (EC) and electrofluorochromic (EFC) properties opening avenues in the development of multifunctional optoelectronic devices. The example of carbazole, a polycyclic aromatic hydrocarbon consisting of two six-membered benzene rings fused on either side of a five-membered nitrogen-containing ring is interesting. When combined with dibenzofuran, the original carbazoledibenzofuran derivatives display both EC and EFC properties [17] From the EFC point of view, it was shown that the fluorescence intensity of these carbazole-dibenzofuran derivatives can be reversibly modulated from their redox states. Accordingly, the starting emissive neutral compounds become non-emissive when reduced in the corresponding radical anions.

Thienoviologen are also compounds displaying interesting EC and EFC properties. The first examples of electrofluorochromic $\pi$-conjugated ionic liquid crystals based on thienoviologens substituted by long alkyl chains were reported in 2014 [18]. Electrofluorescence emission/extinction could be observed several times upon repeated On/Off switching cycles.

Compared to the above-described molecules, Nile Red is mostly known as a lipophilic stain because it is not emissive in most polar solvents, but can be intensely fluorescent when located in a lipid-rich environment. Moreover, Nile Red is a highly fluorescent solvatochromic dye [19]. As the polarity of the solvent increases, the absorption and emission spectra exhibit a bathochromic shift to longer wavelengths. Moreover, it was established that fluorescence quantum efficiency decreases in solvents prone to form hydrogen bonds [20]. Recently, Nile Red was used to track the attachment of microdroplets (filled with this fluorogenic species) onto carbon fibers [21]. More precisely, it was used to fluorescently and electrochemically label an organic-inwater emulsion, where the organic phase was an ionic liquid / toluene mixture. Under these conditions, the fluorescence intensity of the surface bound particles appeared to switch off and on as a function of the applied potential. The two-electron / twoproton reduction of the starting Nile Red compound led to a nonor weakly-fluorescent product. Conversely, the fluorescence intensity of the droplets was found to increase upon oxidation demonstrating the reversibility of the process.
Though reversible electrochemical fluorescence modulation is particularly interesting and sought in the development of electrofluorochromic devices, irreversible processes can also be relevant notably in the discrimination between species internalized and not internalized in lipid vesicles. This approach was recently developed to quantify amounts of cell-penetrating peptides (CPP) that had crossed vesicular lipid membranes [22]. CPP were labeled with NBD (7-nitrobenz-2-oxa-1,3-diazole), a small organic dye displaying a strong fluorescence in non-polar media such as phospholipids. In a typical experience, NBDlabelled peptides were first incubated with large unilamellar vesicles (100 $\mathrm{nm}$ in diameter). Then, the fluorescence emitted by non-internalized peptides was cleanly switched off through the electrochemical reduction of the NBD nitro group whereas internalized NBD-CPP remained fluorescent. Accordingly, the NBD-labeled peptides that had been internalized into the vesicles could be easily quantified from the residual fluorescence. Importantly, this discrimination proved to be efficient not only when the lipid membrane was in gel phase, but also in fluid phase, demonstrating the beneficial contribution of electrochemistry compared to chemical reduction (e.g. using dithionite, $\mathrm{S}_{2} \mathrm{O}_{4}{ }^{2-}$ as the chemical reducing agent) [23]. As shown in Figure 3, the use of dithionite when vesicular lipid membranes were under fluid gel indiscriminately led to a switch off of all the NBD-labelled peptides (internalized and externalized) while electrochemistry only switched off the remaining external peptides leading thus to a clear discrimination between both peptide populations. This work demonstrated how electrochemically-controlled fluorescence could unambiguously quantify the proportion of internalized peptides without interferences often observed with reducing agents.

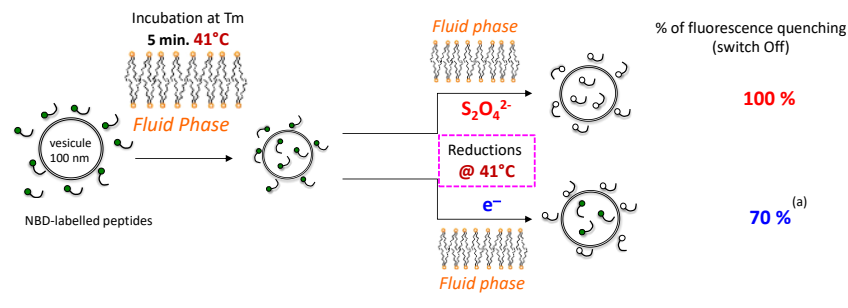

Figure 3. Compared to the chemical switching off of NBD-labelled peptides by dithionite (a chemical reducer), the electrochemical procedure allowed a clear and clean discrimination between internalized and non-internalized CPP under fluid phase [22]. (a) With Tat (peptide sequence: YGRKKRRQRRR) $30 \%$ of the peptide was considered as internalized (unpublished results).

Interestingly, this work was further successfully extended to NBD-labelled phospholipids $(P)$ in view of discriminating between outer and inner leaflets of vesicles [24]. Indeed, this distinction is impossible with usual fluorescence techniques such as FRAP (Fluorescence Recovery After Photobleaching) or FLIP (Fluorescence Loss In Photobleaching) due to limitations in optics and poor laser beam focusing resolution. Accordingly, three kinds of vesicles made of 1,2-dioleoyl-sn-glycero-3-phosphoglycerol (DOPG) phospholipids (95 mol\%), a classical anionic 
phospholipid used to prepare endosome models, and of a small fraction (5 mol\%) of 1,2-dipalmitoyl-sn-glycero-3phosphoethanolamine-N-(7-nitro-2-1,3-benzoxadiazol-4-yl) (NBD-PE) were investigated as a function of the localization of NBD fluorescent lipid: (a) either on the outer, (b) or on the inner, (c) or on both inner/outer leaflets. After verifying both the integrity of the investigated vesicle and its contact with a biotinylated transparent electrode surface made of ITO (Indium Tin Oxide, 10 $\mathrm{nm}$ in thickness), the working electrode was polarized at a potential value $(-0.9 \mathrm{~V}$ vs. $\mathrm{Ag} / \mathrm{AgCl})$ sufficiently negative to reduce the NBD nitro group and turn NBD-PE to its non-fluorescent state (Figure 4).

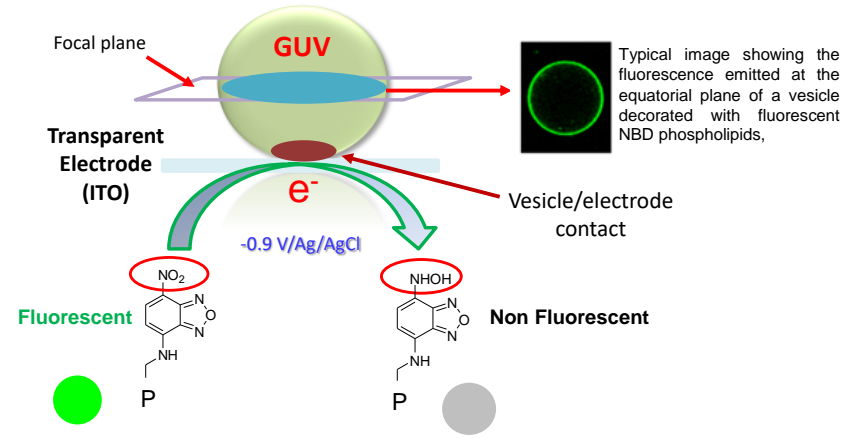

Figure 4. Selective electrochemical bleaching of the outer leaflet of NBD labelled micrometric vesicles.

The fluorescence intensity was monitored at the equatorial plane of the vesicle (i.e. out of the reduction/bleached area) by taking confocal fluorescence microscopy images every 30 seconds. As shown in Figure 5, three different behaviors were obtained depending on the NBD fluorescent probe localization.
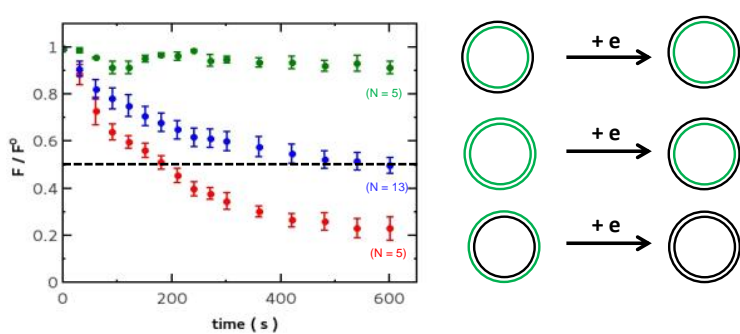

Figure 5. Fluorescence variations as a function of polarization time $(E=-0.9$ $\mathrm{V} / \mathrm{Ag} / \mathrm{AgCl}$ ) obtained at a biotinylated ITO electrode surface for $\left({ }^{\circ}\right)$ inner $(\mathrm{N}=5)$, $(\bullet)$ inner/outer $(\mathrm{N}=13)$, and $(\bullet)$ outer $(\mathrm{N}=5)$ leaflet NBD-labeled DOPG GUVs. The numbers $\mathrm{N}$ between parentheses are those of the GUV analyzed in each case. The error bars represent the standard error (S.E.).

First, fluorescence remained unchanged on vesicles labelled on the inner leaflet $(A)$, confirming that the electrochemical reduction cannot be achieved for probes not in direct contact with the electrode surface (e.g. located inside the vesicle). The slight fluorescence loss (around $10 \%$ ) was very likely due to the fact that a small fraction of fluorescent phospholipids may have been incorporated in the outer leaflet of the vesicle during their preparation [25, 26]. Conversely, a significant fluorescence intensity decrease was observed in the case of outer-leaflet NBDlabelled vesicles (C). In this case, almost $80 \%$ of the fluorescence was quenched after 600 seconds of electrochemical reduction. As a symmetrical situation of the preparation of inner-leaflet-labeled vesicles, outer-leaflet-tagged vesicles finally presented $20 \%$ of the fluorescent phospholipids inserted in the inner leaflet, a proportion consistent with reported values [25]. A 50\% fluorescence extinction was observed on vesicles where both inner and outer leaflets are labeled with NBD-PE.

In conclusion, and contrary to the FLIP technique, these results confirmed that electrochemical bleaching only concerned fluorescent phospholipids localized on the outer-leaflet of the vesicles, thus allowing a discrimination between internal and external lipid bilayers. Furthermore, simulation of the fluorescence loss observed at the equatorial plane of vesicles established that the fluorescence decay was driven by phospholipid-lateral diffusion towards the electrochemical bleached area (i.e the electrode/vesicle interface). This allowed an estimation of the diffusion coefficient of phospholipids located on the outer-leaflet. By analogy with the FLIP technique (Fluorescence Loss In Photobleaching), the FLIE acronym was therefore introduced to qualify this powerful electrochemical quenching method (FLIE for: Fluorescence Loss In Electrobleaching) [24].

\section{Electrochemical switch ON or/and detection of organic fluorogenic molecules}

This section is devoted to organic fluorogenic molecules whose fluorescence can be electrochemically switched either directly or upon electrochemical generation of a $\mathrm{pH}$ gradient that is an important parameter notably in bioanalysis. Moreover, a focus will be done on $\mathrm{pH}$-responsive probes also possessing redox properties in view of concomitant optical/electrochemical detections (Figure 6). Interestingly, most of the redox fluorogenic molecules investigated in electrochemistry have been used for in situ imaging in fluorescence microscopy. Accordingly, the most relevant fluorogenic organic molecules investigated through electrochemistry and fluorescence microscopy are presented in the following.

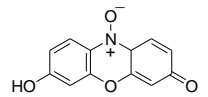

Resazurin (RZ) [29]

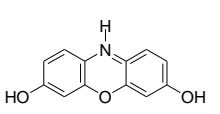

Dihydroresorufin (DH) [31-33]

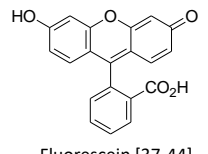

Fluorescein [37-44]<smiles>NCCc1cc(=O)oc2cc(O)c(Cl)cc12</smiles>

FFN102 $[48,49]$
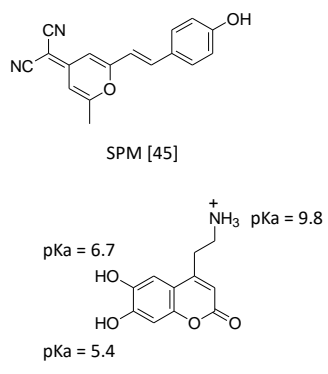

FFN42 [50]
Figure 6. Chemical structures of some relevant organic fluorogenic molecules recently used in molecular electrochemistry. 


\subsection{Direct induced fluorescence modulation}

A first relevant example of a fluorogenic probe undergoing direct electrochemical fluorescence modulation is resazurin (RZ), also called Alamar Blue, which is a blue $\left(\lambda_{\mathrm{abs}}=640 \mathrm{~nm}\right)$ fairly fluorescent redox dye $\left(\lambda_{\text {fluo }}=640 \mathrm{~nm}, \Phi_{\text {fluo }}=0.11\right)$ [27]. Upon electrochemical reduction (bi-electronic process), $R Z$ is irreversibly converted into resorufin (RF), the latter species absorbing at a lower wavelength than the starting molecule $\left(\lambda_{\mathrm{abs}}=\right.$ $570 \mathrm{~nm}$ ) and exhibiting a brighter fluorescent than $\mathrm{RZ}$ ( $\Phi_{\text {fluo }}=0.42$ in aqueous solution at pH 10 [28]) [27, 29] (Figure 7).

$$
\text { Weakly fluorescent }
$$

Figure 7. Resazurin-Resorufin: a typical redox-responsive fluorogenic couple (adapted from ref. [29]). Experimental conditions: aqueous solution; $\mathrm{pH}=10$.

Interestingly, resorufin (RF) is itself reducible into dihydroresorufin $(\mathrm{DH})$, through a reversible 2 electrons process, which neither absorbs visible light nor emits fluorescence. In summary, the reversible reduction of $\mathrm{RF}$ to $\mathrm{DH}$ is responsible for a fluorescence extinction whereas the irreversible reduction of the poorly emitting $\mathrm{RZ}$ to RF is accompanied by an emission enhancement due to the large increase in quantum yield. Based on these properties, the combination of electrochemistry with in situ fluorescence confocal microscopy allowed the reactivity investigation of RF and the reconstruction of its relative concentration profile around the electrode. Thanks to this original approach, surface heterogeneity of the electrode surface could also be potentially studied [29]. Combination of Scanning Electrochemical Microscopy (SECM) and fluorescence microscopy was also successfully achieved using resorufin as fluorophore and redox mediator [30].

Recently, a comproportionation reaction between the nonfluorescent dihydroresorufin $(\mathrm{DH})$ and the oxidized weakly fluorescent $R Z$ species was evidenced and led to the highly fluorescent RF thanks to the combination of electrochemistry and fluorescence confocal laser scanning microscopy which allowed a precise mapping of the fluorescence modulation in the vicinity of an electrode surface [31].

Dihydroresorufin was also used as a fluorogenic indicator in fluorescence-enabled electrochemical microscopy (FEEM) a new electrochemical imaging technique [32]. In this work, the authors correlated the fluorescence intensity of the fluorogenic dye and the electrochemical oxidation current during potential sweep experiments on a bipolar electrode.

This concept of FEEM was extended to bipolar microelectrode arrays [33]. In this work, fluorescence microscopy and bipolar electrodes were used to reveal electrochemical and electrocatalytic activity on large electrochemical arrays. More precisely, a bipolar electrode was used to directly couple a conventional oxidation reaction, e.g. the oxidation of ferrocene, to a special fluorogenic reduction reaction. The generation of the fluorescent product on the cathodic pole enables one to directly monitor an electrochemical process with optical microscopy.

The same group has also investigated 3D diffusion layers by correlating fluorescence images acquired at the reporting pole of an array of bipolar electrodes with the distance between a microelectrode and the other sensing pole of the array. In other words, fluorescence-enabled electrochemical microscopy was employed to image transient concentration profiles of redox species electrogenerated at ultramicroelectrodes [34].

\subsection{Indirect induced fluorescence modulation}

In some cases, the fluorescence of fluorogenic probes can be indirectly activated. This is particularly the case of $\mathrm{pH}$ responsive probes whose fluorescence depends on the $\mathrm{pH}$ of the solution. Actually, fluorescein is a typical molecule used by electrochemists when a production/consumption of protons is triggered at the level of an electrode. Fluorescein, which exhibits strong fluorescence in its basic form [35, 36], was notably used for the establishment of $\mathrm{pH}$ gradients. The approach was developed in the 1990s to monitor, with a wide field fluorescence microscope, reactions producing or consuming protons at the level of an electrode [37-39]. In 2002, following the work reported on the use of confocal Raman microscopy to map molecular diffusion at microelectrodes, [40, 41] three-dimensional $\mathrm{pH}$ gradients were successfully imaged at electrode surfaces using a confocal laser scanning microscope that improved the axial and lateral resolutions. [42] In this case, the local $\mathrm{pH}$ changes caused by the electrochemical reduction of benzoquinone to hydroquinone were evidenced thanks to the presence of fluorescein, which displayed a $\mathrm{pH}$-dependent fluorescent signal Confocal $\mathrm{pH}$ measurements in solution were also performed later in the presence of a scanning electrochemical microscope [43]

Recently, fluorescein, which displays exalted fluorescence under basic conditions, was used in an original sensing concept allowing delocalized detection of biorelevant molecules (1,4naphthoquinone and dopamine) at bipolar electrodes. The approach is based on the generation of local $\mathrm{pH}$ gradients which allow the indirect detection of redox-active molecules due to a modulation of the fluorescence intensity in the vicinity of the bipolar electrode. Accordingly, an oxidation is taking place at the anodic pole of the bipolar electrode, while protons are consumed at the cathodic extremity. The consumption of $\mathrm{H}^{+}$locally increases the $\mathrm{pH}$, leading to enhanced fluorescence compared to the background intensity [44].

A similar approach was recently developed for visualizing cancer cell surface glycoprotein [45]. In this case, the device consisted in an anodic sensing cell and a cathodic reporting cell connected together by a screen-printed electrode patterned on poly(ethylene terephthalate) membrane. In the sensing cell, anti-MUC1 antibody immobilized on a chitosan-multiwalled carbon nanotube (CSMWCNT)-modified anodic bipolar electrode channel was used for capturing mucin-1 (MUC1) or MCF-7 cancer cells. Then ferrocene $(\mathrm{Fc})$-labeled mucin 1 aptamers were introduced through hybridization. Under an applied voltage, the ferrocene was oxidized and the electroactive molecules of 1,4-benzoquinone $(B Q)$ in the cathodic reporting cell were reduced. This produced a strongly basic 1,4-benzoquinone anion radical $\left(\mathrm{BQ}^{-}\right)$, which turned on the fluorescence of $\mathrm{pH}$-responsive molecules of (2-(2(4-hydroxystyryl)-6-methyl-4Hpyran-4-ylidene)malononitrile) (SPM) coexisting in the cathode reporting cell for both spectrophotometric detection and imaging [45]. 


\subsection{Fluorogenic coumarin derivatives also possessing redox properties for concomitant optical/electrochemical detection of exocytotic release}

The design of redox organic fluorescent or fluorogenic molecules requires a particular attention when bioanalysis perspectives are envisioned. Within this context, important parameters such as (i) the nature of the investigated biological mechanism and (ii) the ability of the fluorescent/fluorogenic probe to be uptaken by the investigated cells must be taken into consideration before synthesizing the probe.

The quest for $\mathrm{pH}$-responsive fluorogenic probes displaying independent redox and fluorescent properties is a typical example in the case of vesicular exocytosis [46]. Accordingly, the development of unique dual electrofluorescent probes was carried out to investigate this important biological mechanism through the combination of amperometry and total internal reflection fluorescence microscopy (TIRFM). On the one hand, amperometry provides quantitative information on the amount of secreted electroactive molecules, with sub-millisecond temporal resolution that matches the fast kinetics of exocytotic release. On the other hand, TIRFM is capable of revealing the distribution of secretory vesicles within a single cell, with tens of nanometers spatial resolution, and can track their location during the exocytotic process in real-time.

Historically, in the context of this coupling strategy, single exocytosis events were first investigated using independent electrochemical (serotonine) and fuorescent (GFP) probes [47, 48]. However, the use of two distinct probes prevented a quantitative analysis of the release ignoring the precise relative and absolute proportion of both probes in secretory vesicles (only $\sim 20 \%$ of correlated simultaneous optical and electrochemical signals were recorded concomitantly). Accordingly, a unique dual electrofluorogenic probe, possessing a coumarin backbone, was recently introduced $[49,50]$. This probe called FFN102 belongs to the family of fluorescent false neurotransmitters (FFN) (i.e. a synthesized analogue of a biogenic neurotransmitter). Under physiological conditions $(\mathrm{pH}=7.4)$, optimal excitation and emission wavelengths of this probe lie at $371 \mathrm{~nm}$ and $456 \mathrm{~nm}$, respectively. This molecule is a pH-responsive fluorescent/electroactive dual probe and its fluorescence intensity increased with $\mathrm{pH}$ especially in a $\mathrm{pH} 5.3$ to $\mathrm{pH} 7.3$ window. Accordingly, during exocytosis, FFN102 diffused out from the acidic intravesicular microenvironment to the neutral extracellular space, leading to fluorescent emissions and to the electrochemical oxidation signals that were simultaneously collected at the transparent ITO electrode surface (Figure 8).

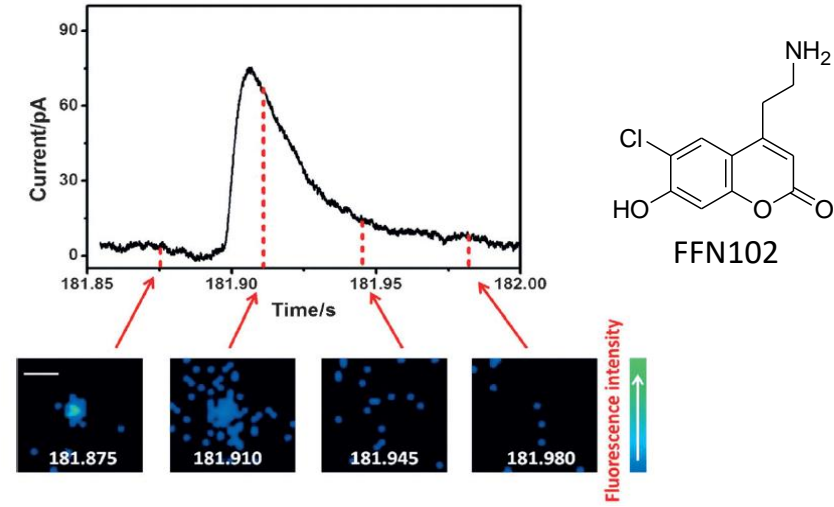

Figure 8. Correlation of amperometric and fluorescence information for a single exocytotic event of FFN102-stained BON N13 cells over an ITO microdevice. Top: An exocytotic event appeared as the current spike in electrochemical detection. Bottom: Sequential pseudocolor TIRFM images of a single exocytotic event viewed as a flash of fluorescence. Scale bar $=500 \mathrm{~nm}$. (Adapted from ref. [49]).

However, the high oxidation potential value of FFN102 at ITO electrodes (+ $900 \mathrm{mV}$ vs. Ag/AgCl) induced electrical noise restricting the advantages of this material. Very recently, a new dual electrofluorescent probe called FFN42 was designed [51] This new electrofluorogenic probe actually acted as an optical/electrochemical dual reporter in the coupling method, especially with longer excitation/emission wavelengths and/or lower oxidation potential. Furthermore, pKas of the three acid functions (hydroxyl groups in positions 6 and 7, respectively; amonium group in position 4) were determined (Figure 6). From the electrochemical point of view, and compared to FFN102, the FFN42 probe is oxidized at $+0.45 \mathrm{~V}$ vs. $\mathrm{Ag} / \mathrm{AgCl}$ on ITO electrodes. The electrochemical detection of FFN42 at a less anodic potential value than FFN102 (+900 mV vs. $\mathrm{Ag} / \mathrm{AgCl})$ is ascribed to the replacement of the chlorine group by a second hydroxy group in position 6 of the coumarin nucleus. This stronger electrondonating group is responsible of promoting easier oxidation, i.e. at lower oxidation potential values, contributing in the decrease of the electrical perturbations.

\section{Summary and Outlook.}

This short overview of the electrochemically-promoted fluorescence modulation of organic fluorescent or fluorogenic molecules shows that this emerging field is very active. This is clearly illustrated through the smart uses of canonical molecules or the design of new ones. Within this context, it is also noteworthy that instrumental setups and methodologies aimed at combining/synchronizing electrochemical commands and fluorescence microscopy/spectroscopy play a crucial role to allow the collection of time- and space-resolved information on various systems. The unique sensitivity of luminescent techniques requires they proceed at specific locations and within well-defined time windows and such properties perfectly match the general features of electrochemistry, making the design of electrochemically-controlled luminescent molecules essential in the future. 


\section{Acknowledgements}

This work has been supported in part by CNRS (UMR 8640), Ecole Normale Supérieure (PSL Research University), Sorbonne Université, the French Ministry of Research, "Emergences Ville de Paris 2014" Grant and Institut Universitaire de France Junior 2015 Fellowship Program.

Keywords: Analytical Methods • Fluorescence • Fluorescent Probes • Molecular Electrochemistry

[1] F. Miomandre, Curr. Opin. Electrochem. 2020, 24, 56-62.

[2] H. Al-Kutubi, H.R. Zafarani, L. Rassaei, K. Mathwig, Eur. Polym. J. 2016, 83, 478-498.

[3] L. Bouffier, T. Doneux, Curr. Opin. Electrochem. 2017, 6, 31-37.

[4] P. Audebert, F. Miomandre, Chem. Sci. 2013, 4, 575-584.

[5] M. Čížková, L. Cattiaux, J. Pandard, M. Guille-Collignon, F. Lemaître, J. Delacotte, J.-M. Mallet, E. Labbé, O. Buriez, Electrochem. Commun. 2018, 97, 46-50

[6] T.-T. Tran, J. Rabah, M.-H. Ha-Thi, E. Allard, S. Nizinski, G. Burdzinski, S. Aloïse, H. Fensterbank, K. Baczko, H. Nasrallah, A. Vallée, G. Clavier, F. Miomandre, T. Pino, R. Méallet-Renault, J. Phys. Chem. B 2020, 124, 9396-9410.

[7] J. L. Shepherd, A. Kell, E. Chung, C. W. Sinclar, M. S. Workentin, D. Bizzotto, J. Am. Chem. Soc. 2004,126, 8329-8335.

[8] J.S. Yu, T.Y. Zhou, J. Electroanal. Chem. 2001, 504, 89-95.

[9] M. Čížková, L. Cattiaux, J.-M. Mallet, E. Labbé, O. Buriez, Electrochim. Acta, 2018, 260, 589-597.

[10] M. Dias, P. Hudhomme, E. Levillain, L. Perrin, Y. Sahin, F.X. Sauvage, C. Wartelle, Electrochem. Commun. 2004, 6, 325-330.

[11] Y. Kim, E. Kim, G. Clavier, P. Audebert, Chem. Commun. 2006, 3612 3614.

[12] A. Loudet, K. Burgess, Chem. Rev. 2007, 107, 4891-4932.

[13] R. Gautam, S.J. Petritis, E. Tomat, Eur. J. Inorg. Chem. 2019, 68-72.

[14] H. Rohr, C. Trieflinger, K. Rurack, J. Daub, Chem. Eur. J. 2006, 12, 689700.

[15] H. Lim, S. Seo, S. Pascal, Q. Bellier, S. Rigaut, C. Park, H. Shin, O. Maury, C. Andraud, E. Kim, Sci. Rep. 2016, 6.

[16] C. Quinton, V. Alain-Rizzo, C. Dumas-Verdes, F. Miomandre, G. Clavier, P. Audebert, RSC Adv., 2014, 4, 34332-34342.

[17] Y. Sun, M. Shi, Y. Zhu, I.F. Perepichka, X. Xing, Y. Liu, C. Yan, H. Meng, ACS Appl. Mater. Interfaces, 2020, 12, 24156-24164.

[18] A. Beneduci, S. Cospito, M. La Deda, L. Veltri, G. Chidichimo, Nat. Commun. 2014, 5.

[19] P. Greenspan, S. D. Fowler, J. Lipid Res. 1985, 26, 781-789.

[20] A. Cser, K. Nagy, L. Biczók, Chem. Phys. Lett. 2002, 360, 473-478.

[21] C. Batchelor-McAuley, C.A. Little, S.V. Sokolov, E. Kätelhön, G. Zampardi, R.G. Compton, Anal. Chem. 2016, 88, 11213-11221.

[22] R. De Oliveira, M. Durand, L. Challier, P. Messina, J.M. Swiecicki, M. Di Pisa, G. Chassaing, S. Lavielle, O. Buriez, E. Labbé, J. Electroanal. Chem. 2017, 788, 225-231

[23] (a) J.-M. Swiecicki, M. Di Pisa, F. Burlina, P. Lecorche, C. Mansuy, G. Chassaing, S. Lavielle, Biopolymers, 2015, 104 (5), 533-543. (b) M. D Pisa, G. Chassaing, J.-M. Swiecicki, Biochemistry, 2015, 54 (2), 194 207.
[24] A.I. Perez Jimenez, L. Challier, E. Aït-Yahiatène, J. Delacotte, E. Labbé O. Buriez, Chem. Eur. J. 2017, 23, 6781-6787.

[25] S. Pautot, B. J. Frisken, D. A. Weitz, Proc. Natl. Acad. Sci. USA 2003 100, 10718 - 10721 .

[26] A. Yamada, M. Le Berre, K. Yoshikawa, D. Baigl, ChemBioChem. 2007 $8,2215-2218$

[27] G.V. Porcal, M.S. Altamirano, C.A. Glusko, S.G. Bertolotti, C.M. Previtali, Dyes Pigm. 2011, 88, 240-246.

[28] G.V. Porcal, C.M. Previtali, S.G. Bertolotti, Dyes Pigm. 2009, 80 206-211.

[29] T. Doneux, L. Bouffier, B. Goudeau, S. Arbault, Anal. Chem. 2016, 88, 6292-6300.

[30] L. Guerret-Legras, J.F. Audibert, I.M. Gonzalez Ojeda, G.V. Dubacheva, F. Miomandre, Electrochim. Acta, 2019, 305, 370-377.

[31] A. de Poulpiquet, B. Goudeau, P. Garrigue, N. Sojic, S. Arbault, T. Doneux, L. Bouffier, Chem. Sci., 2018, 9, 6622-6628.

[32] S.M. Oja, J.P. Guerrette, M.R. David, B. Zhang, Anal. Chem. 2014, 86 6040-6048.

[33] J.P. Guerrette, S.J. Percival, B. Zhang, J. Am. Chem. Soc. 2013, 135, 855-861.

[34] S.M. Oja, B. Zhang, Anal. Chem. 2014, 86, 12299-12307.

[35] R. Sjöback, J. Nygren, M. Kubista, Spectrochim. Acta Part A, 1995, 51, L7-L21.

[36] X.F. Zhang, J.L. Zhang, L.M. Liu, J. Fluoresc. 2014, 24, 819-826.

[37] R. C. Engstrom, S. Ghaffari, H. Qu, Anal. Chem. 1992, 64, 2525-2529.

[38] W. J. Bowyer, J. Xie, R. C. Engstrom, Anal. Chem. 1996, 68, 2005-2009.

[39] J. E. Vitt, R. C. Engstrom, Anal. Chem. 1997, 69, 1070-1076.

[40] C. Amatore, F. Bonhomme, J. L. Bruneel, L. Servant, L. Thouin, Electrochem. Commun. 2000, 2, 235-239.

[41] C. Amatore, F. Bonhomme, J. L. Bruneel, L. Servant, L. Thouin, J. Electroanal. Chem. 2000, 484, 1-17.

[42] S. Cannan, I. D. Macklam, P. R. Unwin, Electrochem. Commun. 2002, 4 886-892.

[43] F.-M. Boldt, J. Heinze, M. Diez, J. Petersen, M. Borsch, Anal. Chem 2004, 76, 3473-3481

[44] L. Bouffier, T. Doneux, B. Goudeau, A. Kuhn. Anal. Chem. 2014, 86, 3708-3711.

[45] Z. Tian, L. Mi, Y. Wu, F. Shao, M. Zou, Z. Zhou, S. Liu. Anal. Chem. 2019, 91, 7902-7910.

[46] M. Guille-Collignon, F. Lemaître, Trends Anal. Chem. 2020, 132, 116055

[47] C. Amatore, S. Arbault, Y. Chen, C. Crozatier, F. Lemaître, Y. Verchier, Angew. Chem. Int. Ed. 2006, 45, 4000-4003.

[48] A. Meunier, O. Jouannot, R. Fulcrand, I. Fanget, M. Bretou, E. Karatekin, S. Arbault, M. Guille, F. Darchen, F. Lemaître, C. Amatore, Angew. Chem. Int. Ed. 2011, 50, 5081-5084.

[49] X. Liu, A. Savy, S. Maurin, L. Grimaud, F. Darchen, D. Quinton, E. Labbé O. Buriez, J. Delacotte, F. Lemaître, M. Guille-Collignon, Angew. Chem. Int. Ed. 2017, 56, 2366-2370.

[50] X. Liu, L. Hu, N. Pan, L. Grimaud, E. Labbe, O. Buriez, J. Delacotte, F. Lemaitre, M. Guille-Collignon, Biophys. Chem. 2018, 235, 48-55.

[51] J. Pandard, N. Pan, D.H. Ebene, T. Le Saux, E. Ait-Yahiatène, X. Liu, L. Grimaud, O. Buriez, E. Labbé, F. Lemaître, M. Guille-Collignon. ChemPlusChem. 2019, 84, 1578-1586. 
(1) 